\section{Commentary: Timing of coronary artery bypass grafting after ST elevation myocardial infarction: All judgment, no magic}

\author{
Rami Akhrass, MD, Jaikirshan Khatri, MD, and \\ Faisal G. Bakaeen, MD
}

Up to $50 \%$ of patients presenting with ST elevation myocardial infarction (STEMI) have multivessel disease, and 30\% have diabetes mellitus, ${ }^{1}$ both of which are proven to benefit long-term from coronary artery bypass grafting (CABG). However, in the acute setting, the priority is expeditious revascularization to salvage as much myocardium as possible, and percutaneous coronary intervention (PCI) gains the upper hand. ${ }^{1}$ When PCI is not feasible or surgical revascularization is necessary, $\mathrm{CABG}$ can be life-saving but is associated with increased perioperative risk.

In this issue of the Journal, Elbadawi and colleagues ${ }^{2}$ provide perhaps the largest analysis of the utilization of CABG during the index hospitalization for STEMI in the US. $^{2}$ Over a 15 -year period (2002-2016), there was a significant decline in the number of CABG operations as a result of widespread adoption of PCI and also coinciding with the decreasing incidence of STEMI.

Interestingly, the performance of CABG at hospitalization day $\geq 3$ increased slightly over time, along with an increase in the utilization of mechanical circulatory support and pre-CABG PCI. Operating on day 2 was not associated with increased perioperative risk in the later years of the study, ${ }^{2}$ corroborating findings reported by others. ${ }^{3}$ However, surgery on day 1 was associated with increased risk and was more likely performed among patients with anterior myocardial infarction and cardiogenic shock. ${ }^{2}$

\footnotetext{
From the Coronary Center, Heart, Vascular and Thoracic Institute, Cleveland Clinic, Cleveland, Ohio.

Disclosures: The authors reported no conflicts of interest.

The Journal policy requires editors and reviewers to disclose conflicts of interest and to decline handling or reviewing manuscripts for which they may have a conflict of interest. The editors and reviewers of this article have no conflicts of interest.

Received for publication March 24, 2021; revisions received March 24, 2021; accepted for publication March 25, 2021; available ahead of print March 30, 2021.

Address for reprints: Rami Akhrass, MD, Department of Thoracic and Cardiovascular Surgery, Heart, Vascular and Thoracic Institute, Cleveland Clinic, 9500 Euclid Ave, Cleveland, OH 44195 (E-mail: akhrasr@ccf.org).

J Thorac Cardiovasc Surg 2023;165:684-5

0022-5223/ $\$ 36.00$

Copyright (c) 2021 by The American Association for Thoracic Surgery

https://doi.org/10.1016/j.jtcvs.2021.03.083
}

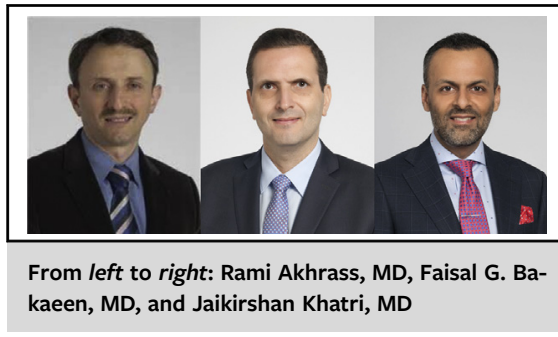

CENTRAL MESSAGE
The use of coronary artery
bypass grafting (CABG) is
declining during hospitalization
for ST elevation myocardial
infarction (STEMI). When CABG
is performed, comorbidities are
common and mortality is highest
on day 1, coinciding with
increased prevalence of anterior
MI and cardiogenic shock.

The study has notable limitations, some of which are highlighted by the authors, including the lack of granularity regarding the scenarios driving decision-making in the timing of surgery. There are no data on the anatomic severity and complexity of the coronary lesions or the myocardial mass at risk. In addition, there are sparse data on antithrombotic drugs and their reversal and on blood loss and transfusions. Bleeding is a dreaded complication associated with increased morbidity and mortality in CABG patients. In stable patients, it may be reasonable to delay the surgery to allow time for antithrombotic medication "wash out" to reduce the risk of bleeding.

Not captured by this study are patients who are stabilized medically or with PCI of the culprit lesion and complete surgical revascularization deferred to a future admission. Right-sided STEMI with significant right ventricular dysfunction is a particularly high-risk scenario that can benefit from delaying surgery in an otherwise stable patient. A semielective CABG at a later date can offer a better opportunity for multiarterial grafting, a strategy associated with improved long-term outcomes. ${ }^{4,5}$

Ongoing ischemia mandates emergency surgery when PCI is not possible, particularly when a large myocardial territory is at risk. Temporary mechanical circulatory support is useful for stabilizing patients and reversing shock 
while awaiting surgery, for aiding postsurgical recovery, or for providing a bridge to more advanced durable heart failure therapies if the presentation is late and the infarct has completed with no added benefit for revascularization.

In summary, delaying CABG in an effort to reduce the risk of bleeding or to allow for a "cooling-off" period after STEMI is governed by imperfect science and driven primarily by patient-related factors and surgical judgment. If the clinical scenario mandates emergency surgery (day 1), then the risks are high and likely unavoidable. On the other hand, if waiting is a viable option, then there is nothing magical about waiting until day 2 , day 3 , or any other day for that matter. It is about balancing the risk:benefit ratio, which varies from one case to another.

\section{References}

1. O'Gara PT, Kushner FG, Ascheim DD, Casey DE Jr, Chung MK, de Lemos JA, et al. $2013 \mathrm{ACCF} / \mathrm{AHA}$ guideline for the management of ST-elevation myocardial infarction: a report of the American College of Cardiology Foundation/American Heart Association task force on practice guidelines. Circulation. 2013;127: e362-425.

2. Elbadawi A, Elzeneini M, Elgendy I, Megaly M, Omer M, Jimenez E, et al. Coronary artery bypass grafting after acute ST-elevation myocardial infarction. $J$ Thorac Cardiovasc Surg. 2023;165:672-83.e10.

3. Nichols EL, McCullough JN, Ross CS, Kramer RS, Westbrook BM, Klemperer JD, et al. Optimal timing from myocardial infarction to coronary artery bypass grafting on hospital mortality. Ann Thorac Surg. 2017;103:162-71.

4. Aldea GS, Bakaeen FG, Pal J, Fremes S, Head SJ, Sabik J, et al. The Society of Thoracic Surgeons clinical practice guidelines on arterial conduits for coronary artery bypass grafting. Ann Thorac Surg. 2016;101:801-9.

5. Lytle BW, Blackstone EH, Loop FD, Houghtaling PL, Arnold JH, Akhrass R, et al Two internal thoracic artery grafts are better than one. J Thorac Cardiovasc Surg. 1999; $117: 855-72$
See Article page 672.

\section{Commentary: The times they are a-changin': Coronary artery bypass grafting following acute ST-elevation myocardial infarction}

\author{
D. Alan Herbst, MD, and Pavan Atluri, MD
}

Acute ST-elevation myocardial infarction (STEMI) is a common indication for emergency room visits and hospitalization in the United States. ${ }^{1}$ Percutaneous coronary intervention (PCI) is the therapy of choice to rapidly restore blood flow and reduce infarction volume. Coronary artery bypass grafting $(\mathrm{CABG})$ is a less frequently used modality of reperfusion and is reserved for patients with multivessel disease, left main disease, and post-myocardial infarction complications. Urgent CABG is recommended as rescue therapy after complicated or failed PCI when patients are experiencing ongoing ischemia and cardiogenic shock. ${ }^{2}$ Despite these

\footnotetext{
From the Division of Cardiovascular Surgery, Department of Surgery, The Hospital of the University of Pennsylvania, Philadelphia, Pa.

Disclosures: The authors reported no conflicts of interest.

The Journal policy requires editors and reviewers to disclose conflicts of interest and to decline handling or reviewing manuscripts for which they may have a conflict of interest. The editors and reviewers of this article have no conflicts of interest.

Received for publication April 1, 2021; revisions received April 1, 2021; accepted for publication April 5, 2021; available ahead of print April 20, 2021.

Address for reprints: Pavan Atluri, MD, Division of Cardiovascular Surgery, Department of Surgery, The Hospital of the University of Pennsylvania, 3400 Spruce St,

Philadelphia, PA 19104 (E-mail: pavan.atluri@uphs.upenn.edu).

J Thorac Cardiovasc Surg 2023;165:685-6

$0022-5223 / \$ 36.00$

Copyright (c) 2021 by The American Association for Thoracic Surgery

https://doi.org/10.1016/j.jtcvs.2021.04.004
}

Check for updates

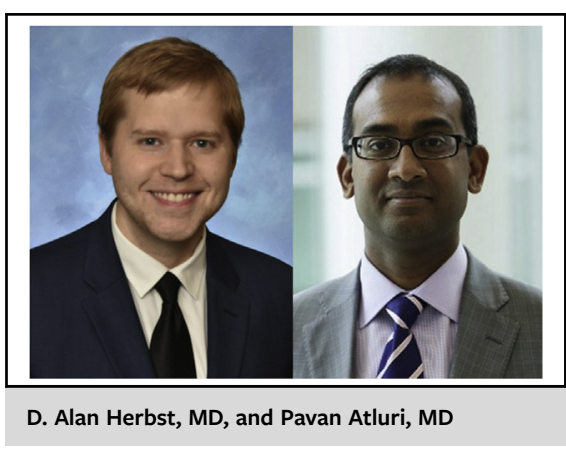

CENTRAL MESSAGE

Using the largest inpatient database in the United States, the authors report changes in trends in the surgical timing and management of acute ST-elevation myocardial infarction over the past 20 years.

recommendations, no consensus exists to dictate the optimal timing after presentation to perform surgery.

In this issue of the Journal, Elbadawi and colleagues ${ }^{3}$ report changes in trends over the past 20 years for the surgical management of acute STEMI. The authors conducted a retrospective review of the National Inpatient Sample (NIS) database, which represents $20 \%$ of annual hospitalizations in the United States. Their analysis spanned from 2002 to 